\title{
The role of surgical resection in the management of newly diagnosed brain metastases: a systematic review and evidence-based clinical practice guideline
}

\author{
Steven N. Kalkanis - Douglas Kondziolka - Laurie E. Gaspar • \\ Stuart H. Burri · Anthony L. Asher · Charles S. Cobbs · Mario Ammirati • \\ Paula D. Robinson · David W. Andrews · Jay S. Loeffler • Michael McDermott • \\ Minesh P. Mehta $\cdot$ Tom Mikkelsen $\cdot$ Jeffrey J. Olson • Nina A. Paleologos • \\ Roy A. Patchell $\cdot$ Timothy C. Ryken • Mark E. Linskey
}

Received: 7 September 2009/Accepted: 8 November 2009/Published online: 4 December 2009

(C) The Author(s) 2009. This article is published with open access at Springerlink.com

\begin{abstract}
Question

Should patients with newly-diagnosed metastatic brain tumors undergo open surgical resection versus whole brain radiation therapy (WBRT) and/or other treatment modalities such as radiosurgery, and in what clinical settings?

Target population

These recommendations apply to adults with a newly diagnosed single brain metastasis amenable to surgical resection.

\section{Recommendations}

Surgical resection plus WBRT versus surgical resection alone

Level 1 Surgical resection followed by WBRT represents a superior treatment modality, in terms of improving tumor control at the original site of the metastasis and in the brain overall, when compared to surgical resection alone.

\section{Surgical resection plus WBRT versus $S R S \pm$ WBRT}

Level 2 Surgical resection plus WBRT, versus stereotactic radiosurgery (SRS) plus WBRT, both represent effective treatment strategies, resulting in relatively equal survival rates. SRS has not been assessed from an evidence-based standpoint for larger lesions $(>3 \mathrm{~cm})$ or for those causing significant mass effect ( $>1 \mathrm{~cm}$ midline shift).

Level 3 Underpowered class I evidence along with the preponderance of conflicting class II evidence suggests that SRS alone may provide equivalent functional and survival outcomes compared with resection + WBRT for patients with single brain metastases, so long as ready
\end{abstract}

S. N. Kalkanis $(\bowtie)$

Department of Neurosurgery, Henry Ford Health System,

2799 West Grand Blvd, K-11, Detroit, MI 48202, USA

e-mail: kalkanis@neuro.hfh.edu; skalkan1@hfhs.org detection of distant site failure and salvage SRS are possible.

Note The following question is fully addressed in the WBRT guideline paper within this series by Gaspar et al. Given that the recommendation resulting from the systematic review of the literature on this topic is also highly relevant to the discussion of the role of surgical resection in the management of brain metastases, this recommendation has been included below.

\section{Question}

Does surgical resection in addition to WBRT improve outcomes when compared with WBRT alone?

\section{Target population}

This recommendation applies to adults with a newly diagnosed single brain metastasis amenable to surgical resection; however, the recommendation does not apply to relatively radiosensitive tumors histologies (i.e., small cell lung cancer, leukemia, lymphoma, germ cell tumors and multiple myeloma).

\section{Recommendation}

\section{Surgical resection plus WBRT versus WBRT alone}

Level 1 Class I evidence supports the use of surgical resection plus post-operative WBRT, as compared to WBRT alone, in patients with good performance status (functionally independent and spending less than $50 \%$ of time in bed) and limited extra-cranial disease. There is insufficient evidence to make a recommendation for patients with poor performance scores, advanced systemic disease, or multiple brain metastases.

\section{Kondziolka}

Department of Neurological Surgery, University of Pittsburgh Medical Center, Pittsburgh, PA, USA 
Keywords Brain metastases - Surgical resection . Stereotactic radiosurgery $\cdot$ Radiotherapy . Systematic review $\cdot$ Practice guideline

\section{Rationale}

A significant proportion of adults diagnosed with cancer will develop brain metastases. According to the 2008 American Cancer Society Registry, approximately 1.4 million Americans are diagnosed with cancer every year [1] and up to $40 \%$ of these patients-over a half million people annually-will go onto develop one or more brain metastases [2]. Of these patients, approximately one-third will be potential candidates for surgical resection.

The outcome for patients with brain metastases is generally poor, with median survivals following WBRT alone in the range of 3-6 months [3-5]. Given this poor prognosis, considerable efforts have been made to explore additional or alternative treatment modalities that have the potential to improve survival, quality of life and local tumor control.

For patients with a single accessible brain metastasis, surgical resection followed by post-operative WBRT has been compared to WBRT alone in three randomized control trials (RCTs) [3-5]. The evidence for this combined treatment approach is reviewed in the guideline paper in this

\section{E. Gaspar}

Department of Radiation Oncology, University of

Colorado-Denver, Denver, CO, USA

\section{S. H. Burri}

Department of Radiation Oncology, Carolinas Medical Center, Charlotte, NC, USA

\section{A. L. Asher}

Department of Neurosurgery, Carolina Neurosurgery

and Spine Associates, Charlotte, NC, USA

\section{S. Cobbs}

Department of Neurosciences, California Pacific Medical Center, San Francisco, CA, USA

\section{Ammirati}

Department of Neurosurgery, Ohio State University

Medical Center, Columbus, OH, USA

\section{P. D. Robinson}

McMaster University Evidence-based Practice Center,

Hamilton, ON, Canada

D. W. Andrews

Department of Neurosurgery, Thomas Jefferson University, Philadelphia, PA, USA

\section{J. S. Loeffler}

Department of Radiation Oncology, Massachusetts

General Hospital, Boston, MA, USA series by Gaspar et al. [6] Because the data from these randomized comparisons of WBRT alone, versus surgical resection followed by post-operative WBRT, addresses the role of surgical resection in the management of patients with a newly diagnosed brain metastasis, this paper will refer to this evidence in its recommendations for the role of surgical resection.

The advent of stereotactic radiosurgery (SRS) has provided a new and less invasive local treatment modality that, like surgical resection, has the ability to treat brain metastases while sparing healthy brain tissue. A key area that this paper will address is the role of surgical resection compared to SRS in the initial management of patients with brain metastases.

The overall objectives of this paper are:

1. To systematically review the evidence available for the following treatment comparisons for patients with a newly diagnosed brain metastasis. Please note that "surgery" implies open surgical resection.

- Surgery versus WBRT \pm surgery

- Surgery \pm WBRT or partial brain radiotherapy (RT) versus $\mathrm{SRS} \pm$ WBRT or partial brain RT

- Surgery \pm WBRT versus surgery + SRS

2. To make recommendations based on this evidence for the role of surgery in the management of these patients.

M. McDermott

Department of Neurosurgery, University of California

San Francisco, San Francisco, CA, USA

M. P. Mehta

Department of Human Oncology, University of Wisconsin School of Public Health and Medicine, Madison, WI, USA

T. Mikkelsen

Department of Neurology, Henry Ford Health System, Detroit, MI, USA

\section{J. J. Olson}

Department of Neurosurgery, Emory University School of Medicine, Atlanta, GA, USA

N. A. Paleologos

Department of Neurology, Northshore University Health System, Evanson, IL, USA

\section{R. A. Patchell}

Department of Neurology, Barrow Neurological Institute, Phoenix, AZ, USA

\section{T. C. Ryken}

Department of Neurosurgery, Iowa Spine and Brain Institute, Iowa City, IA, USA

M. E. Linskey

Department of Neurosurgery, University of California-Irvine Medical Center, Orange, CA, USA 


\section{Methods}

\section{Search strategy}

The following electronic databases were searched from 1990 to September 2008: MEDLINE ${ }^{\circledR}$, Embase ${ }^{\circledR}$, Cochrane Database of Systematic Reviews, Cochrane Controlled Trials Registry, and Cochrane Database of Abstracts of Reviews of Effects. A broad search strategy using a combination of subheadings and text words was employed. The search strategy is documented in the methodology paper for this guideline series by Robinson et al. [7]. Reference lists of included studies were also reviewed.

\section{Eligibility criteria}

- Published in English.

- Patients with newly diagnosed brain metastases.

- Fully-published (i.e., not in abstract form) peerreviewed primary comparative studies (These included the following comparative study designs for primary data collection: RCTs, non-randomized trials, cohort studies and case-control studies).

- Study comparisons include one or more of the following:

\section{- Surgery versus WBRT}

- Surgery versus surgery + WBRT

- Surgery \pm WBRT or partial brain RT versus $\mathrm{SRS} \pm$ WBRT or partial brain RT

- Surgery versus surgery + SRS

- Surgery + WBRT versus surgery + SRS

(Where SRS could be single session and fractionated stereotactic radiotherapy)

- Number of study participants with a newly diagnosed brain metastasis $\geq 5$ per study arm for at least two of the study arms.

- Baseline information on study participants is provided by treatment group in studies evaluating interventions exclusively in patients with a newly diagnosed brain metastasis. For studies with mixed populations (i.e., includes participants with conditions other than newly diagnosed brain metastases), baseline information is provided for the intervention sub-groups of participants with a newly diagnosed brain metastasis.

Study selection and quality assessment

Two independent reviewers evaluated citations using a priori criteria for relevance and documented decisions in standardized forms. Cases of disagreement were resolved by a third reviewer. The same methodology was used for full-text screening of potentially relevant papers. Studies which met the eligibility criteria were data extracted by one reviewer and the extracted information was checked by a second reviewer. The PEDro scale [8,9] was used to rate the quality of randomized trials. The quality of comparative studies using non-randomized designs was evaluated using eight items selected and modified from existing scales.

Evidence classification and recommendation levels

Both the quality of the evidence and the strength of the recommendations were graded according to the American Association of Neurological Surgeons (AANS)/Congress of Neurological Surgeons (CNS) criteria. These criteria are provided in the methodology paper for this guideline series.

Guideline development process

The AANS/CNS convened a multi-disciplinary panel of clinical experts to develop a series of practice guidelines on the management of brain metastases based on a systematic review of the literature conducted in collaboration with methodologists at the McMaster University Evidencebased Practice Center.

\section{Scientific foundation}

Overall, 15 publications (14 primary studies [10-23] and one companion paper [24]) met the eligibility criteria. Figure 1 outlines the flow of studies through the review process.

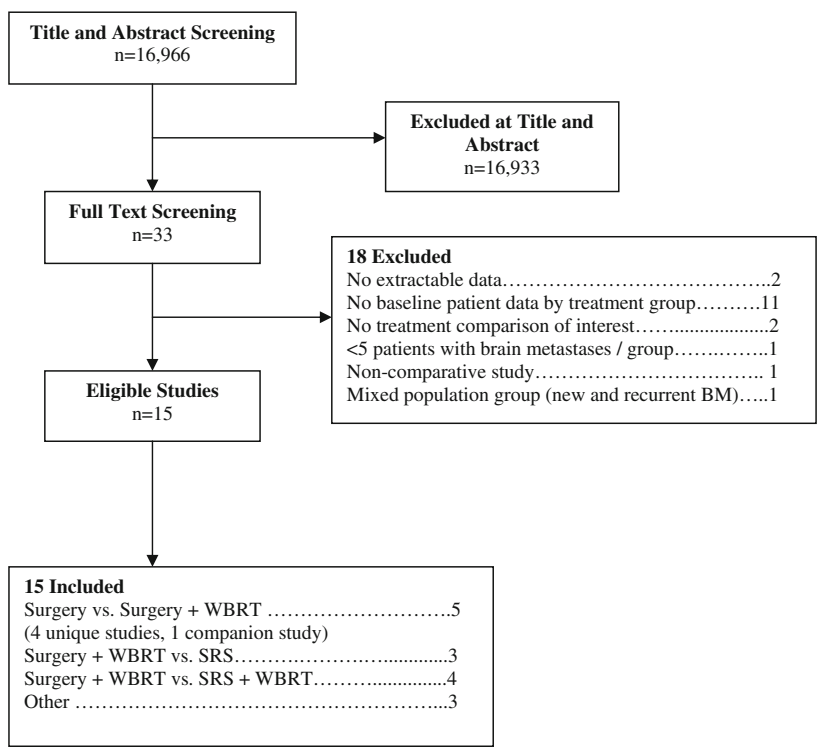

Fig. 1 Flow of studies to final number of eligible studies 
Surgical resection versus surgical resection + WBRT

One RCT [10] and three retrospective cohort studies [11-13] evaluated surgical resection alone compared to surgery plus post-operative WBRT for the initial management of a single brain metastasis (Table 1).

The randomized data available to address this treatment comparison comes from a multi-center trial conducted in the United States by Patchell et al. [10]. The trial randomized adults with Karnofsky performance scores (KPS) $\geq 70$ who had complete resection of a single biopsy-proven brain metastasis, confirmed by MRI, to post-operative WBRT (50.4 Gy in 28 fractions) or no further treatment. Randomization was stratified by the extent of extra-cranial disease and primary tumor type. A total of 95 patients were randomized: 49 patients to post-operative WBRT and 46 patients to observation. Baseline characteristics were wellbalanced between the two groups. Non-small cell lung cancer (NSCLC) was the predominant tumor type (surgery + WBRT: 59\%; surgery alone: 61\%), median KPS was 90 in both groups and approximately one-third of patients had no evidence of extra-cranial disease (surgery + WBRT: $37 \%$; surgery alone: $35 \%$ ). No patient was lost to follow-up and the data was analyzed by intentionto-treat. The primary outcome was tumor recurrence anywhere in the brain.

Fewer patients who received post-operative WBRT experienced a recurrence in the brain compared to those who had surgical resection alone [surgery + WBRT: $9 / 49(18 \%)$ versus surgery: $32 / 46(70 \%) ; P<0.001]$. Recurrence in the

Table 1 Surgery versus surgery + WBRT

\begin{tabular}{|c|c|c|c|c|}
\hline First author (Year) & Interventions & Median survival & $\begin{array}{l}\text { \# pts with recurrence/ } \\
\text { progression }^{\text {a }}\end{array}$ & $\begin{array}{l}\text { Median time to } \\
\text { recurrence/ } \\
\text { progression }\end{array}$ \\
\hline \multicolumn{5}{|l|}{ Randomized trials } \\
\hline Patchell [10] (1998) & $\begin{array}{l}\text { G1: Surgery }(n=46) \\
\text { G2: Surgery }+ \text { WBRT } \\
\quad(n=49)\end{array}$ & $\begin{array}{l}\mathrm{G} 1: 43 \text { wks } \\
\mathrm{G} 2: 48 \text { wks } \\
(\text { Log-rank; } P=\mathrm{NS})\end{array}$ & $\begin{array}{l}\text { At original site: } \\
\text { G1: } 21 / 46(46 \%) \\
\text { G2: } 5 / 49(10 \%)(P<0.001) \\
\text { Overall in brain: } \\
\text { G1: } 32 / 46(70 \%) \\
\text { G2: } 9 / 49(18 \%)(P<0.001)\end{array}$ & $\begin{array}{l}\text { At original site: } \\
\text { G1: } 27 \text { wks } \\
\text { G2: }>50 \text { wks } \\
\quad \text { (Log-rank; } P<0.001 \text { ) } \\
\text { Overall in brain: } \\
\text { G1: } 26 \text { wks } \\
\text { G2: } 220 \text { wks } \\
\text { (Log-rank; } \\
P<0.001)\end{array}$ \\
\hline \multicolumn{5}{|c|}{ Retrospective cohort studies } \\
\hline Armstrong[11] (1994) & $\begin{array}{l}\text { G1: Surgery }(n=32) \\
\text { G2: Surgery }+ \text { WBRT } \\
\quad(n=32) \\
{[\text { matched to G1] }} \\
\text { G3: Surgery }+ \\
\text { WBRT }(n=79) \\
\text { [not matched] }\end{array}$ & $\begin{array}{l}\text { G1: } 14 \text { months } \\
\text { G2: } 10 \text { months } \\
\text { G3: } 15 \text { months } \\
\text { (G1 vs. G2: } \\
\text { Log-rank; } P=\mathrm{NS} \text { ) }\end{array}$ & $\begin{array}{l}\text { At original site: } \\
\text { G1: } 11 / 32(34 \%) \\
\text { G2 + G3: } 25 / 111(23 \%) \\
\text { (G1 vs. } \mathrm{G} 2+\mathrm{G} 3: P=\mathrm{NS}) \\
\text { Overall in brain: } \\
\text { G1: } 38 \% \\
\text { G2: } 47 \% \\
\text { G3: } 42 \%(\mathrm{G} 1 \text { vs. G2: } P=\mathrm{NS})\end{array}$ & NR \\
\hline Hagen [12] (1990) & $\begin{array}{l}\text { G1: Surgery }(n=16) \\
\text { G2: Surgery }+ \text { WBRT } \\
\quad(n=19)\end{array}$ & $\begin{array}{l}\text { G1: } 8.3 \text { months } \\
\text { G2: } 6.4 \text { months } \\
\text { (Test not specified; } \\
\quad P=\text { NS) }\end{array}$ & $\begin{array}{l}\text { At original site: } \\
\text { G1: } 6 / 16(38 \%) \\
\text { G2: } 4 / 19(21 \%)(P=\mathrm{NR}) \\
\text { Overall in brain: } \\
\text { G1: } 11 / 16(69 \%) \\
\text { G2: } 7 / 19(37 \%)(P=\mathrm{NR})\end{array}$ & $\begin{array}{l}\text { At original site: NR } \\
\text { Overall in brain: } \\
\text { G1: } 5.7 \text { months } \\
\text { G2: } 26.6 \text { months } \\
\text { (Test not specified; } \\
\quad P<0.05 \text { ) }\end{array}$ \\
\hline Skibber [13] (1996) & $\begin{array}{l}\text { G1: Surgery }(n=12) \\
\text { G2: Surgery }+ \text { WBRT } \\
\quad(n=22)\end{array}$ & $\begin{array}{l}\text { G1: } 6 \text { months } \\
\text { G2: } 18 \text { months } \\
\text { (Generalized Wilcoxon; } \\
\quad P=0.002)\end{array}$ & $\begin{array}{l}\text { At original site: } \mathrm{NR} \\
\text { Overall in brain: } \\
\text { G1: } 9 / 12(75 \%) \\
\text { G2: } 5 / 22(23 \%)(P=\mathrm{NR})\end{array}$ & NR \\
\hline
\end{tabular}

G1 Group 1, G2 Group 2, G3 Group 3, NR Not reported, NS Not significant, Pts Patients, WBRT Whole-brain radiation therapy

${ }^{a}$ Number of pts with recurrence/progression of brain metastases, unless otherwise specified 
WBRT group was less frequent both at the original site of the brain metastasis [surgery + WBRT: 5/49 (10\%) versus surgery: $21 / 46$ (46\%); $P<0.001]$ and at distant sites in the brain [surgery + WBRT: 7/49 (14\%) versus surgery: 17/46 (37\%); $P<0.01]$ compared to patients who did not receive post-operative WBRT.

The time to any recurrence in the brain was significantly longer in the group that had post-operative WBRT compared to the group that did not (log-rank; $P<0.001$ ). Both the time to recurrence at the original site in the brain (logrank; $P<0.001$ ) and at distant brain sites (log-rank; $P=0.04)$ were significantly longer in the post-operative WBRT group compared to the group that received no further treatment following surgery.

Fewer patients in the WBRT group died as a result of neurological causes than did patients in the surgery alone group [surgery + WBRT: 6/43 (14\%) deaths versus surgery: $17 / 39$ (44\%) deaths; $P=0.003$ ]. Overall survival did not differ significantly between the two groups. Median survival in the surgery + WBRT group was 48 weeks compared to 43 weeks in the group that received no further treatment following surgical resection. This study was not powered for survival, however, which was a secondary and not a primary endpoint. The duration of functional independence (defined as the median time that KPS remain $\geq 70$ ) also did not differ significantly between the two groups (surgery + WBRT: 37 weeks versus surgery: 35 weeks; $P=\mathrm{NS})$.

Surgical resection \pm WBRT or partial brain RT versus stereotactic radiosurgery $(\mathrm{SRS}) \pm$ whole or partial brain RT

One RCT [23] and nine retrospective cohort studies [14-22] met the eligibility criteria for this treatment comparison (Tables 2, 3, 4). All of these studies utilized singledose SRS with one exception [20] which employed fractionated stereotactic radiotherapy. However, in 2006, the American Society for Therapeutic Radiology and Oncology (ASTRO), the American Association of Neurological Surgeons (AANS) and the Congress of Neurological Surgeons (CNS) jointly agreed to define SRS in a way that

Table 2 SRS versus Surgery + WBRT

\begin{tabular}{|c|c|c|c|c|}
\hline First author (Year) & Interventions & Median survival & $\begin{array}{l}\text { \# pts with recurrence/ } \\
\text { progression }^{\mathrm{a}}\end{array}$ & $\begin{array}{l}\text { Median time to recurrence/ } \\
\text { progression }\end{array}$ \\
\hline \multicolumn{5}{|c|}{ Randomized controlled trials } \\
\hline Muacevic [23] (2008) & $\begin{array}{l}\text { G1: SRS }(n=31) \\
\text { G2: Surgery }+ \text { WBRT } \\
\quad(n=33)\end{array}$ & $\begin{array}{l}\text { G1: } 10.3 \text { months } \\
\text { G2: } 9.5 \text { months } \\
\text { (Log-rank; } P=\mathrm{NS} \text { ) }\end{array}$ & $\begin{array}{l}1 \text { yr local control rate: } \\
\text { G1: } 97 \% \\
\text { G2: } 82 \% \\
1 \text { yr distant recurrence rate: } \\
\text { G1: } 26 \% \\
\text { G2: } 3 \%\end{array}$ & $\begin{array}{l}\text { At original site: } \\
\text { Median: NR } \\
\text { (LR curves: log-rank; } \\
\quad P=0.06, \mathrm{NS} \text { ) } \\
\text { At distant brain sites: } \\
\text { Median: NR } \\
\text { (DR curves: log-rank; } \\
P=0.04 \text { ) }\end{array}$ \\
\hline \multicolumn{5}{|c|}{ Retrospective cohort studies } \\
\hline Muacevic [14] (1999) & $\begin{array}{l}\text { G1: SRS }(n=56) \\
\text { G2: Surgery }+ \text { WBRT } \\
\quad(n=52)\end{array}$ & $\begin{array}{l}\mathrm{G} 1: 35 \text { weeks } \\
\mathrm{G} 2: 68 \text { weeks } \\
(\text { Log-rank; } P=\mathrm{NS})\end{array}$ & $\begin{array}{l}1 \mathrm{yr} \text { freedom from LR rate: } \\
\text { G1: } 83 \% \\
\text { G2: } 75 \% \\
1 \text { yr freedom from DR rate: } \\
\text { G1: } 68 \% \\
\text { G2: } 90 \%(P=0.0025)\end{array}$ & $\begin{array}{l}\text { At original site: } \\
\text { G1: Median not reached } \\
\text { G2: Median not reached } \\
\text { (Log-rank; } P=\text { NS) } \\
\text { At distant brain sites: } \\
\text { NR }\end{array}$ \\
\hline Rades [15] (2007) & $\begin{array}{l}\text { G1: SRS }(n=94) \\
\text { G2: Surgery }+ \text { WBRT } \\
\quad(n=112)\end{array}$ & $\begin{array}{l}\text { Median survival: NR } \\
1 \text { yr survival rate: } \\
\text { G1: } 54 \% \\
\text { G2: } 38 \% \\
(\text { Log-rank; } P=\mathrm{NS})\end{array}$ & $\begin{array}{l}1 \text { yr freedom from LR rate: } \\
\text { G1: } 64 \% \\
\text { G2: } 56 \% \\
1 \text { yr freedom from BR rate: } \\
\text { G1: } 49 \% \\
\text { G2: } 44 \%\end{array}$ & $\begin{array}{l}\text { At original site: } \\
\text { Median: NR } \\
\text { (LR curves: log-rank; } \\
P=\mathrm{NS} \text { ) } \\
\text { Overall in brain: } \\
\text { Median: NR } \\
\text { (BR curves: log-rank; } \\
P=\mathrm{NS} \text { ) }\end{array}$ \\
\hline
\end{tabular}

$\overline{B R}$ Brain recurrence (local + distant), $D R$ Distant recurrence in brain, $G 1$ Group 1, G2 Group 2, LR Local recurrence at original site in brain, $N R$ Not reported, NS Not significant, Pts Patients, SRS Stereotactic radiosurgery, WBRT Whole-brain radiation therapy

${ }^{a}$ Number of pts with recurrence/progression of brain metastases, unless otherwise specified 
includes both traditional single dose SRS, as well as multidose SRS up to five doses (2-5 doses) [25, 26]. Additionally, while the majority of these SRS studies were conducted using Gamma Knife radiosurgery, there is no evidence to suggest that other modes of delivery of SRS would lead to different outcomes.

\section{(a) Surgical resection + WBRT versus SRS}

A small RCT [23] and two retrospective cohorts [14, 15] specifically compared resection plus post-operative WBRT to SRS alone for the initial treatment of a newly diagnosed brain metastasis (Table 2).

The randomized data is from a multi-center RCT conducted in Germany by Muacevic et al. [23], which closed prematurely due to poor patient accrual. A total of 64 out of the planned 242 adult patients with single, small $(\leq 3 \mathrm{~cm})$ operable brain metastases and a KPS $\geq 70$ were randomized to receive SRS alone $(n=31)$ or surgical resection followed by WBRT $(n=33)$. Baseline prognostic variables were well-balanced between the two groups. All of the participants received the treatment as allocated and none were lost to follow-up.

The primary outcome, overall survival, did not differ significantly between the two groups. Median survival in the surgery + WBRT group was 9.5 months, compared to 10.3 months in the group that received SRS. In terms of secondary outcomes, duration of freedom from local recurrence did not significantly differ between the two groups (log-rank; $P=0.06$; NS). The 1 year local control rate was $82 \%$ in the surgery + WBRT group and $96.8 \%$ in the SRS group. Freedom from recurrence at distant brain sites was significantly longer in the group that had surgical resection plus WBRT compared to the group that received SRS (logrank; $P=0.04)$. Finally, the overall number of neurological deaths was not significantly different between the groups.

\section{(b) Surgical resection + WBRT versus $S R S+W B R T$}

No prospective studies were identified that met the eligibility criteria for this treatment comparison. Four retrospective cohort studies [16-19] that compared surgical resection plus WBRT to SRS plus WBRT met the inclusion criteria (Table 3). In two of these studies [16, 19] the majority, but not all, of the subjects received WBRT.

In three of the studies [17-19], overall survival did not differ significantly between the resection plus WBRT group compared with the group that received SRS plus WBRT. In one study [16], overall survival was significantly longer for patients that received surgery plus WBRT compared to patients that had SRS and WBRT (log-rank; $P=0.0018$ ), although patients in the SRS arm were generally poorer resection candidates. In this study, freedom from local recurrence was also significantly longer in the surgery plus WBRT group (log-rank; $P=0.0001$ ). Schoggl et al. [18] reported a significant benefit in duration of freedom from local recurrence for patients that received SRS and WBRT compared to patients that had surgical excision plus WBRT $(P<0.05)$, supporting the findings in the Garell et al. [17] study as well. O'Neill et al. [19] reported no local recurrences in the SRS group compared to a $58 \%$ local recurrence rate in the surgical resection group $(P=0.020)$. These studies also demonstrated no significant difference between groups in the duration of freedom from recurrence at distant brain sites [16, 18].

\section{Surgical resection \pm WBRT versus surgical resection + SRS}

No studies were identified that met the eligibility criteria for this treatment comparison.

\section{Summary and discussion}

Surgical resection plus WBRT versus WBRT alone

The WBRT guideline paper by Gaspar et al. [6] outlines in detail the evidence supporting the addition of WBRT after surgical resection. Please refer to this paper for a further discussion of why surgical resection plus post-operative WBRT represents a superior treatment modality as compared to WBRT alone, in patients with good performance status (functionally independent and spending less than $50 \%$ of time in bed) and limited extra-cranial disease. There is insufficient evidence to make a recommendation for patients with poor performance scores, advanced systemic disease, or multiple brain metastases.

Surgical resection + WBRT versus surgical resection

Class I evidence is available (in the Patchell RCT [10]) to support a level 1 recommendation for patients with a single brain metastasis amenable to surgical resection. The class I evidence supports the use of WBRT following surgical resection. Control of extra-cranial disease is not required for patients to benefit from aggressive forms of local therapy, but generally patients required a KPS of at least 70 to be eligible for the studies and the anticipated interventions. Recurrence in the brain, as measured overall, at the original site or at distant brain sites, were all significantly lower in the group that received adjuvant post-operative WBRT than the group undergoing surgical resection alone.

However, both overall survival and time spent in an independent status (KPS $>70$ ) did not differ significantly 
Table 3 Surgery + WBRT versus SRS + WBRT

\begin{tabular}{|c|c|c|c|c|}
\hline First author (Year) & Interventions & Median survival & \# pts with recurrence/progression ${ }^{\mathrm{a}}$ & $\begin{array}{l}\text { Median time to } \\
\text { recurrence/progression }\end{array}$ \\
\hline \multicolumn{5}{|c|}{ Retrospective cohort studies } \\
\hline Bindal [16] (1996) & $\begin{array}{l}\text { G1: Surgery } \pm \text { WBRT }^{\mathrm{b}} \\
\quad(n=62)[\text { matched to } \mathrm{G} 2] \\
\mathrm{G} 2: \mathrm{SRS} \pm \mathrm{WBRT}^{\mathrm{b}} \\
\quad(n=31)\end{array}$ & $\begin{array}{l}\text { G1: } 16.4 \text { months } \\
\text { G2: } 7.5 \text { months } \\
\text { (Log-rank; } P=0.0018 \text { ) }\end{array}$ & $\begin{array}{l}1 \text { yr freedom from LR rate: } \\
\text { G2 poorer than G1 } \\
\text { [Data: NR] } \\
1 \text { yr freedom from DR rate: } \\
\text { G1: } 75 \% \\
\text { G2: } 69 \%\end{array}$ & $\begin{array}{l}\text { At original site: } \\
\text { G1: Median not reached } \\
\text { G2: } 6 \text { months } \\
\text { (Log-rank; } P=0.0001) \\
\text { At distant brain sites: } \\
\text { G1: Median not reached } \\
\text { G2: Median not reached } \\
\text { (Log-rank; } P=\mathrm{NS})\end{array}$ \\
\hline Garell [17] (1999) & $\begin{array}{l}\text { G1: Surgery }+ \text { WBRT } \\
\quad(n=37) \\
\text { G2: SRS + WBRT }(n=8)\end{array}$ & $\begin{array}{l}\text { G1: } 8 \text { months } \\
\text { G2: } 12.5 \text { months } \\
\text { (Log-rank } P=\mathrm{NS} \text { ) }\end{array}$ & NR & NR \\
\hline Schogg1 [18] (2000) & $\begin{array}{l}\text { G1: Surgery }+ \text { WBRT } \\
\quad(n=66) \\
\text { G2: SRS + WBRT } \\
\quad(n=67)\end{array}$ & $\begin{array}{l}\text { G1: } 9 \text { months } \\
\text { G2: } 12 \text { months } \\
\text { (Test unclear' } P=\mathrm{NS} \text { ) }\end{array}$ & $\begin{array}{l}\text { At original site: } \\
\text { G1: } 11 / 66(17 \%) \\
\text { G2: } 3 / 67(5 \%)(P=\mathrm{NR}) \\
\text { At distant brain sites: } \\
\text { G1: } 10 / 66(15 \%) \\
\text { G2: } 7 / 67(10 \%)(P=\mathrm{NR})\end{array}$ & $\begin{array}{l}\text { At original site: } \\
\text { G1: } 3.9 \text { months } \\
\text { G2: } 4.9 \text { months } \\
\text { (Test unclear; } P<0.05 \text { ) } \\
\text { At distant brain sites: } \\
\text { G1: } 3.7 \text { months } \\
\text { G2: } 4.4 \text { months } \\
\text { (Test unclear; } P=\mathrm{NS} \text { ) }\end{array}$ \\
\hline O’Neill [19] (2003) & $\begin{array}{l}\text { G1: Surgery } \pm \text { WBRT }^{\mathrm{b}} \\
\quad(n=74) \\
\text { G2: SRS } \pm \mathrm{WBRT}^{\mathrm{b}} \\
\quad(n=23)\end{array}$ & $\begin{array}{l}\text { Median survival: NR } \\
1 \text { yr survival rate: } \\
\text { G1: } 62 \% \\
\text { G2: } 56 \% \\
(\text { Log-rank; } P=\mathrm{NS})\end{array}$ & $\begin{array}{l}\text { At original site: } \\
\text { G1: } 11 / 64(17 \%) \\
\text { G2: } 0 / 21(0 \%)(P=\mathrm{NR}) \\
\text { Overall in brain: } \\
\text { G1: } 19 / 64(30 \%) \\
\text { G2: } 6 / 21(29 \%)(P=\mathrm{NR})\end{array}$ & NR \\
\hline
\end{tabular}

$D R$ Distant recurrence in brain, G1 Group 1, G2 Group 2, LR Local recurrence at original site in brain, NR Not reported, NS Not significant, Pts Patients, SRS Stereotactic radiosurgery, WBRT Whole-brain radiation therapy

${ }^{\text {a }}$ Number of pts with recurrence/progression of brain metastases, unless otherwise specified

b WBRT use similar at baseline in both groups

between the groups. The Patchell study did show a reduction in neurologic deaths $(P=0.003)$ in the patients who received WBRT in addition to surgical resection. In patients with distant metastatic disease, rates of neurological death may in fact provide a more useful endpoint for this clinical comparison. Nonetheless, the lack of a survival difference has offered support to a common but unsubstantiated treatment plan encompassing surgery alone with close observation, delaying WBRT for so-called "salvage therapy" at recurrence. No evidence-based justification currently exists for such expectant observation.

\section{Surgical resection + WBRT versus SRS}

While the surgical resection versus radiosurgery comparison produces less clear-cut results, class I evidence based on the AANS/CNS scale does address this clinical question. However, the Muacevic RCT [23] closed early and only enrolled approximately one-quarter of the proposed participants and was thus underpowered to detect a survival difference, if in fact one exists. Given the small sample size, the authors of the RCT reported that by their calculations, the trial was only sufficiently powered to detect an overall survival difference of $38 \%$ or greater between the two groups $80 \%$ of the time. It is difficult to offer firm guidelines based upon a prematurely closed study.

Furthermore, duration of freedom from local recurrence did not significantly differ between the two groups (log-rank; $P=0.06$; NS) with the 1 year local control rate at $82 \%$ in the resection + WBRT group and $96.8 \%$ in the SRS group. A larger trial will, perhaps, provide more definitive information regarding this outcome given the borderline $P$-value of 0.06 . In general, though, it is 
Table 4 Other included studies of surgery \pm radiotherapy versus SRS \pm radiotherapy

\begin{tabular}{|c|c|c|c|c|}
\hline First author (year) & Interventions & Median survival & $\begin{array}{l}\text { \# pts with recurrence/ } \\
\text { progression }^{\text {a }}\end{array}$ & $\begin{array}{l}\text { Median time to } \\
\text { recurrence/progression }\end{array}$ \\
\hline \multicolumn{5}{|l|}{ Retrospective cohorts } \\
\hline Ikushima [20] (2000) & $\begin{array}{l}\text { G1: Fractionated SRS }(n=10) \\
\text { G2: Surgery }+ \text { RT }(n=11) \\
\text { G3: RT }(n=14) \\
{[\mathrm{RT}=\text { WBRT or local }]}\end{array}$ & $\begin{array}{l}\text { G1: } 25.6 \text { months } \\
\text { G2: } 18.7 \text { months } \\
\text { G3: } 4.3 \text { months } \\
\text { (Univariate analysis: } \\
\text { G1 vs. } \mathrm{G} 2+\mathrm{G} 3: P=0.05 \text { ) }\end{array}$ & $\begin{array}{l}1 \text { yr local control rate: } \\
\text { G1: } 90 \% \\
\text { G2: } 88 \% \\
\text { G3: NR }\end{array}$ & $\begin{array}{l}\text { At original site: } \\
\text { Median: NR } \\
\text { (LR curves: log-rank; } \\
\quad P=\text { NS) }\end{array}$ \\
\hline Shinoura [21] (2002) & $\begin{array}{l}\text { G1: SRS }(n=28) \\
\text { G2: Surgery }+ \text { RT }(n=35) \\
{[\mathrm{RT}=\text { WBRT or local }]}\end{array}$ & $\begin{array}{l}\text { G1: } 8.2 \text { months } \\
\text { G2: } 34.4 \text { months } \\
\text { (Log-rank; } P<0.0001)\end{array}$ & $\begin{array}{l}\text { \# lesions that recurred at } \\
\text { original site: } \\
\text { G1: } 16 / 52(31 \%) \\
\text { G2: } 14 / 46(30 \%) \\
(P \text {-value: } \mathrm{NR})\end{array}$ & $\begin{array}{l}\text { Mean time at original } \\
\text { site: } \\
\text { G1: } 7.2 \text { months } \\
\text { G2: } 25 \text { months } \\
\text { (Log-rank; } P=0.0199 \text { ) }\end{array}$ \\
\hline Wang [22] (2002) & $\begin{array}{l}\text { G1: Surgery } \\
\text { G2: WBRT } \\
\text { G3: SRS } \\
\text { G4: SRS + WBRT }\end{array}$ & $\begin{array}{l}\text { G1: } 43 \text { wks } \\
\text { G2: } 37 \text { wks } \\
\text { G3: } 67 \text { wks } \\
\text { G4: } 91 \text { wks } \\
\text { (Log-rank } P<0.00001 \text { ) }\end{array}$ & $\begin{array}{l}1 \text { month local tumor } \\
\text { control: } \\
\text { G1: } 89 \% \\
\text { G2: } 88 \% \\
\text { G3: } 93 \% \\
\text { G4: } 96 \%\end{array}$ & $\begin{array}{l}\text { NR } \\
.\end{array}$ \\
\hline
\end{tabular}

G1 Group 1, G2 Group 2, G3 Group 3, G4 Group 4, LR Local recurrence at original site in brain, NR Not reported, Pts Patients, RT Radiotherapy, $S R S$ Stereotactic radiosurgery, WBRT Whole-brain radiation therapy

${ }^{a}$ Number of pts with recurrence/progression of brain metastases, unless otherwise specified

often difficult to determine local recurrence in a study comparing surgical resection versus SRS; in the SRS literature, a remaining enhancing abnormality stable over time is considered "local control," but may overestimate the true long-term control associated with SRS.

In terms of distant brain recurrence, freedom from recurrence at distant brain sites was significantly longer in the group that had resection plus WBRT, as expected, compared to the group that received local therapy in the form of SRS (log-rank; $P=0.04)$. In this and other studies, patient accrual lagged behind proposed enrollment in the study design phase because of strong physician preference for either surgical resection or SRS.

The lower distant brain recurrence rates in the WBRT arm makes intuitive sense since these patients are receiving effective treatment for potential lesions elsewhere in the brain, unlike those in the SRS arm. In terms of survival, however, class II evidence suggests that survival is not decreased when WBRT is not given as initial therapy (for details, refer to the guideline paper in this series by Linskey et al. [27], which addresses the role of SRS for newly diagnosed brain metastases).

Quality of life, including potential neuro-cognitive treatment effects, represents another important question that still needs to be addressed: does recurrence impact quality of life since survival appears to be unchanged between the two treatment arms? A recently-closed randomized Phase III trial by the European Organization for the Research and Treatment of Cancer (EORTC \#22952) achieved full accrual of its target 340 patients and compared no radiotherapy to WBRT for 1-3 brain metastases from solid tumor after resection or SRS; these results, when available, may provide powerful evidence for the role of WBRT.

\section{Surgical resection + WBRT versus SRS + WBRT}

Four retrospective cohort studies [16-19] provide evidence for this treatment comparison. While class II evidence does exist for these interventions, all of the studies are retrospective rather than prospective, and they yield conflicting results in terms of overall survival and duration of freedom from local recurrence. However, Class II evidence does suggest that larger lesions $(>3 \mathrm{~cm}$ in maximum diameter) or those causing significant mass effect $(>1 \mathrm{~cm}$ midline shift) may have better outcomes with surgical resection. Radiosurgery is recommended for single surgically inaccessible lesions measuring $<3 \mathrm{~cm}$ in maximum diameter.

Surgical resection \pm WBRT versus surgical resection + SRS

No studies were identified for this treatment comparison and as such, no evidence-based recommendations can be made regarding one approach compared to the other. 


\section{Conclusions and future directions}

Class I evidence suggests that surgical resection followed by WBRT represents a superior treatment modality, in terms of improving tumor control at the original site of the metastasis and in the brain overall, when compared to surgical resection alone. As reviewed by Gaspar et al., in the WBRT guideline paper in this series, class I evidence also supports the use of surgical resection plus post-operative WBRT in patients with good performance status and limited extra-cranial disease compared to WBRT alone (refer to the WBRT guideline paper in this series for further detail).

The advent of SRS, though, has provided several clinically important permutations and combination treatment options for patients with brain metastases, some of which clearly improve recurrence rates and survival as well. Guideline papers in this series by Gaspar et al., and Linskey et al., address some of these relevant treatment comparisons incorporating surgical resection, WBRT, SRS and the concept of delaying WBRT for salvage therapy without adverse sequelae. Class II evidence suggests that larger lesions $(>3 \mathrm{~cm})$ or those causing significant mass effect $(>1 \mathrm{~cm}$ midline shift) may have better outcomes with surgical resection, whereas radiosurgery may offer slightly better local control rates for radioresistant lesions (i.e., melanoma, renal cell, etc.). However, because of underpowered class I evidence in the resection + WBRT versus SRS alone comparison, the authors could only make a level 3 recommendation suggesting that SRS alone may provide equivalent functional and survival outcomes compared with resection + WBRT for patients with single brain metastases, so long as ready detection of distant site failure and salvage SRS are possible.

Additional prospective randomized studies, such as the Phase 3 EORTC study mentioned previously (referenced below-5) and two recently closed randomized trials comparing surgical resection to SRS (referenced below-1, 2 ), will be required to more definitively assess treatment outcomes.

One notable treatment combination in need of further study involves the concept of applying SRS to the surgical resection cavity post-operatively instead of post-operative WBRT. Although many large cancer centers around the country have recently adopted this practice, no robust prospective data yet exists to support a few retrospective case series suggesting that both local control rates and even survival are enhanced by this post-operative SRS option.

The role of surgical resection for multiple brain metastases

While surgical resection of more than one brain metastasis has been performed in cases of significant mass effect from more than one lesion, and in cases where two or more lesions are accessible through the same craniotomy approach, no robust comparative data exists to evaluate the role of surgical resection for multiple brain metastases. Future studies incorporating the role of resection for more than one brain metastasis, with or without additional adjuvant therapy, will also help clarify whether the benefits of resection discussed above apply to multiple lesions.

Other important future directions include designing trials with a focus on quality of life and patient functional status as primary outcomes, rather than only recurrence rates or survival. Given that small differences in survival rates for a given treatment option potentially minimize significant differences in quality of life for a particular therapy, an analysis of a wider range of outcome parameters may help better inform practitioners, and our patients, when making critical treatment decisions. Histology-specific brain metastasis trials may also help answer important therapeutic questions regarding radioresistant lesions versus other common histologies. Most studies thus far have not specifically addressed differences in histological subtype despite the fact that management of extracranial malignancies differs widely based on cancer histology (i.e., breast versus lung versus renal cell, etc.).

The following is a list of major ongoing or recently closed clinical trials pertaining to the use of surgery that evaluate treatment comparisons addressed by this guideline paper for the management of newly diagnosed brain metastases.

1. Surgery versus radiosurgery to treat metastatic brain tumors

Official Title: A Prospective, Randomized Trial Comparing Surgery Versus Radiosurgery for the Treatment of Metastatic Brain Tumors

Status: Completed

Clinicaltrials.gov Identifier: NCT00075166

Location: United States

Sponsors and Collaborators: National Institute of Neurological Disorders and Stroke (NINDS)

2. 2. Surgery versus stereotactic radiosurgery in the treatment of single brain metastasis: a randomized trial Official Title: Surgery Versus Stereotactic Radiosurgery in the Treatment of Single Brain Metastasis: A Randomized Trial

Status: Completed

Clinicaltrials.gov Identifier: NCT00460395

Principal Investigator: Frederick F. Lang, M.D., University Of Texas MD Anderson Cancer Center

Location: United States

Sponsors and Collaborators: M.D. Anderson Cancer Center 
3. A Trial of Postoperative Whole Brain Radiation Therapy versus Salvage Stereotactic Radiosurgery Therapy for Metastasis

Official Title: Randomized Phase III Trial of Postoperative Whole Brain Radiation Therapy Compared With Salvage Stereotactic Radiosurgery in Patients With One to Four Brain Metastasis: Japan Clinical Oncology Group Study (JCOG 0504)

Status: Recruiting (Phase III)

Clinicaltrials.gov Identifier: NCT00280475

Principal Investigator: Takamasa Kayama, MD, PhD

Yamagata University Faculty of Medicine

Location: Japan (21 locations)

Sponsors and Collaborators: Japan Clinical Oncology Group, Japanese Ministry of Health, Labor and Welfare

4. A Trial Comparing Radiosurgery With Surgery for Solitary Brain Metastases

Official Title: A Randomised Trial of Surgery Plus Whole Brain Radiotherapy (WBRT) Versus Radiosurgery Plus WBRT for Solitary Brain Metastases

Status: Recruiting (Phase III)

Clinicaltrials.gov Identifier: NCT00124761

Principal Investigator: Daniel Roos, FRANZCR, Royal

Adelaide Hospital

Location: Australia

Sponsors and Collaborators: Royal Adelaide Hospital

5. Adjuvant Radiation Therapy in Treating Patients With Brain Metastases

Official Title: Phase III Trial on Convergent Beam Irradiation of Cerebral Metastases

Status: Active, not recruiting (Phase III)

Clinicaltrials.gov Identifier: NCT00002899

Principal Investigators: Rolf-Peter Mueller, MD Medizinische Universitaetsklinik I at the University of Cologne Riccardo Soffietti, MD Universita Degli Studi di Turin

Location: Europe (33 locations)

Sponsors and Collaborators: European Organization for Research and Treatment of Cancer

\begin{abstract}
Acknowledgments We would like to acknowledge the contributions of the McMaster Evidence-based Practice Center (EPC), Dr. Parminder Raina, (Director). Dr. Lina Santaguida (Co-Associate Director, Senior Scientist) led the EPC staff, which was responsible for managing the systematic review process, searching for and retrieving, reviewing, data abstraction of all articles, preparation of the tables and the formatting and editing of the final manuscripts.
\end{abstract}

Disclaimer of liability The information in these guidelines reflects the current state of knowledge at the time of completion. The presentations are designed to provide an accurate review of the subject matter covered. These guidelines are disseminated with the understanding that the recommendations by the authors and consultants who have collaborated in their development are not meant to replace the individualized care and treatment advice from a patient's physician(s). If medical advice or assistance is required, the services of a competent physician should be sought. The proposals contained in these guidelines may not be suitable for use in all circumstances. The choice to implement any particular recommendation contained in these guidelines must be made by a managing physician in light of the situation in each particular patient and on the basis of existing resources.

Disclosures All panel members provided full disclosure of conflicts of interest, if any, prior to establishing the recommendations contained within these guidelines.

Open Access This article is distributed under the terms of the Creative Commons Attribution Noncommercial License which permits any noncommercial use, distribution, and reproduction in any medium, provided the original author(s) and source are credited.

\section{References}

1. American Cancer Society (2008) Cancer facts and figures 2008. http://www.cancer.org/docroot/stt/content/stt_1x_cancer_facts_ and_figures_2008.asp

2. Gavrilovic IT, Posner JB (2005) Brain metastases: epidemiology and pathophysiology. J Neurooncol 75(1):5-14

3. Patchell RA, Tibbs PA, Walsh JW, Dempsey RJ, Maruyama Y, Kryscio RJ et al (1990) A randomized trial of surgery in the treatment of single metastases to the brain. $\mathrm{N}$ Engl $\mathrm{J}$ Med 322(8):494-500

4. Mintz AH, Kestle J, Rathbone MP, Gaspar L, Hugenholtz H, Fisher B et al (1996) A randomized trial to assess the efficacy of surgery in addition to radiotherapy in patients with a single cerebral metastasis. Cancer 78(7):1470-1476

5. Vecht CJ, Haaxma-Reiche H, Noordijk EM, Padberg GW, Voormolen JH, Hoekstra FH et al (1993) Treatment of single brain metastasis: radiotherapy alone or combined with neurosurgery? Ann Neurol 33(6):583-590

6. Gaspar LE, Mehta MP, Patchell RA, Burri SH, Robinson PD, Morris RE et al (2009) The role of whole brain radiation therapy in the management of newly diagnosed brain metastases: A systematic review and evidence-based clinical practice guideline. J Neurooncol. doi:10.1007/s11060-009-0060-9

7. Robinson PD, Kalkanis SN, Linskey ME, Santaguida PL (2009) Methodology used to develop the AANS/CNS management of brain metastases evidence-based clinical practice parameter guidelines. J Neurooncol. doi:10.1007/s11060-009-0059-2

8. Centre for Evidence-Based Physiotherapy (2009) Physiotherapy evidence database (PEDro). http://www.pedro.org.au/. Last Accessed Jan 2009

9. Maher CG, Sherrington C, Herbert RD, Moseley AM, Elkins M (2003) Reliability of the PEDro scale for rating quality of randomized controlled trials. Phys Ther 83(8):713-721

10. Patchell RA, Tibbs PA, Regine WF, Dempsey RJ, Mohiuddin M, Kryscio RJ et al (1998) Postoperative radiotherapy in the treatment of single metastases to the brain: a randomized trial. JAMA 280(17):1485-1489

11. Armstrong JG, Wronski M, Galicich J, Arbit E, Leibel SA, Burt M (1994) Postoperative radiation for lung cancer metastatic to the brain. J Clin Oncol 12(11):2340-2344

12. Hagen NA, Cirrincione C, Thaler HT, DeAngelis LM (1990) The role of radiation therapy following resection of single brain metastasis from melanoma. Neurology 40(1):158-160 
13. Skibber JM, Soong SJ, Austin L, Balch CM, Sawaya RE (1996) Cranial irradiation after surgical excision of brain metastases in melanoma patients. Ann Surg Oncol 3(2):118-123

14. Muacevic A, Kreth FW, Horstmann GA, Schmid-Elsaesser R, Wowra B, Steiger HJ et al (1999) Surgery and radiotherapy compared with gamma knife radiosurgery in the treatment of solitary cerebral metastases of small diameter. J Neurosurg 91(1):35-43

15. Rades D, Bohlen G, Pluemer A, Veninga T, Hanssens P, Dunst J et al (2007) Stereotactic radiosurgery alone versus resection plus whole-brain radiotherapy for 1 or 2 brain metastases in recursive partitioning analysis class 1 and 2 patients. Cancer 109(12):25152521

16. Bindal AK, Bindal RK, Hess KR, Shiu A, Hassenbusch SJ, Shi WM et al (1996) Surgery versus radiosurgery in the treatment of brain metastasis. J Neurosurg 84(5):748-754

17. Garell PC, Hitchon PW, Wen BC, Mellenberg DE, Torner J (1999) Stereotactic radiosurgery versus microsurgical resection for the initial treatment of metastatic cancer to the brain. J Radiosurg 2(1): 1-5

18. Schoggl A, Kitz K, Reddy M, Wolfsberger S, Schneider B, Dieckmann K et al (2000) Defining the role of stereotactic radiosurgery versus microsurgery in the treatment of single brain metastases. Acta Neurochir 142(6):621-626

19. O’Neill BP, Iturria NJ, Link MJ, Pollock BE, Ballman KV, O'Fallon JR (2003) A comparison of surgical resection and stereotactic radiosurgery in the treatment of solitary brain metastases. Int J Radiat Oncol Biol Phys 55(5):1169-1176

20. Ikushima H, Tokuuye K, Sumi M, Kagami Y, Murayama S, Ikeda $\mathrm{H}$ et al (2000) Fractionated stereotactic radiotherapy of brain metastases from renal cell carcinoma. Int $\mathbf{J}$ Radiat Oncol Biol Phys 48(5):1389-1393

21. Shinoura N, Yamada R, Okamoto K, Nakamura O, Shitara N (2002) Local recurrence of metastatic brain tumor after stereotactic radiosurgery or surgery plus radiation. J Neurooncol 60(1):71-77

22. Wang LG, Guo Y, Zhang X, Song SJ, Xia JL, Fan FY et al (2002) Brain metastasis: Experience of the Xi-Jing Hospital. Stereotact Funct Neurosurg 78(2):70-83

23. Muacevic A, Wowra B, Siefert A, Tonn JC, Steiger HJ, Kreth FW (2008) Microsurgery plus whole brain irradiation versus Gamma Knife surgery alone for treatment of single metastases to the brain: a randomized controlled multicentre phase III trial. J Neurooncol 87(3):299-307

24. Regine WF, Rogozinska A, Kryscio RJ, Tibbs PA, Young AB, Patchell RA (2004) Recursive partitioning analysis classifications I and II: applicability evaluated in a randomized trial for resected single brain metastases. Am J Clin Oncol 27(5):505-509

25. Barnett GH, Linskey ME, Adler JR, Cozzens JW, Friedman WA, Heilbrum MP et al (2007) Stereotactic radiosurgery-an organized neurosurgery-sanctioned definition. J Neurosurg 106(1):1-5

26. American Society for Radiation Oncology (2007) Stereotactic radiosurgery definition. In: ASTRO news. Int J Radiat Oncol Biol Phys 67(4): 1280

27. Linskey ME, Andrews DW, Asher AL, Burri SH, Kondziolka DS, Robinson PD et al (2009) The role of stereotactic radiosurgery in the management of newly diagnosed brain metastases: a systematic review and evidence-based clinical practice guideline. J Neurooncol. doi:10.1007/s11060-009-0073-4 